Volume 8, No.6, November - December 2019

International Journal of Advanced Trends in Computer Science and Engineering

Available Online at http://www.warse.org/IJATCSE/static/pdf/file/ijatcse108862019.pdf

https://doi.org/10.30534/ijatcse/2019/108862019

\title{
A Concept of Cassava Phytoplasma Disease Monitoring and Mapping System using GIS and SMS Technology
}

\author{
Irma T. Plata, Edward B. Panganiban, Bryan B. Bartolome, Freddie E. Rick Labuanan, and Allan C. Taracatac \\ College of Computing Studies, Information and Communication Technology, Isabela State University \\ Echague, Isabela, Philippines, demeters@ isu.edu.ph
}

\begin{abstract}
Monitoring systems are developed for controlling specific technology implemented in an organization. It basically functions to analyze operations, performance, and provide possible detection and alert in times of problems and difficulties. The convenience of using a monitoring system in detecting and preventing the spread of Cassava Phytoplasma disease (CPD) may be used by farmers to immediately isolate the infected plants to avoid possible spread to other areas of the plantation, thus, possibly alleviating the decrease in production and yields. Monitoring results can prevent or minimize incidents of CPD through early preventive measures. The System Alerts and Notification that reach the user about a certain status with the integration of the Short Message Service (SMS) Technology, and Graphical Visualization in order to facilitate the analysis of the data through Geographic Information System (GIS) graphicalmapping representation. The concept is mainly focused on monitoring, mapping and disseminate preventive measures for CPD and with the addition of the concept of embedded system drone-based image processing for detection and recognition of CPD that serves as the data entry of the system. The integration of the GIS and SMS Technology is well fitted to use in the development and the concept of CPD Monitoring and Mapping System. The concept of GIS makes the monitoring and mapping of CPD readable, predictable, and interactive. Furthermore, the SMS makes wide and flexible dissemination of preventive measures in any categorical aspect group of users. For future studies to be conducted, consider a standard evaluation instrument to foresee the outcome effectiveness of this concept research paper.
\end{abstract}

Key words: Cassava Phytoplasma Disease (CPD), GIS, Mapping, Monitoring system, SMS notification

\section{INTRODUCTION}

In addition to rice and corn, cassava (Manihot esculenta Crantz) is one of the important agricultural crops in the Philippines. It can be used as human food and ingredients for feeds. It has also numerous industrial uses that include starch, flour, and bio-ethanol. Cassava is a perennial shrub one of the leading food crops and feeds plants of the world in the tropical and sub-tropical continent like Asia which is mainly cultivated by limited resource farmers [1].
However, a type of virus called Cassava Phytoplasma Disease (CPD) also known as Witches' Broom disease is presently manifesting to some cassava fields which is a current serious threat to the cassava industry. The disease is named after the broom-like leaf proliferation and it affects the top of cassava plants. Accordingly, CPD-infected plants can be determined through naked eyes, it shows the change in color like the yellowing or reddening of leaves and internodes are shrinking. Once infected, there is underdeveloped growth, unnecessary duplication of shoots, and smaller leaves are present. Its effect may be reduced by cassava root starch contents that merely affect the crop yield value and directly may affect farmers' income and livelihood [2].

Phytoplasma interferes with plant development. In the manifestations or symptoms appear as early as two to three months, there will have $100 \%$ loss as there will be no more production of roots. If the symptoms appear at the later stages like five to six months or onward, there will be a reduction in yield of up to $40 \%$ [3]. In the study conducted by the Philippine Root Crop Research in 2015, they found out that there is a high demand for cassava used for foods, feeds, and industrial uses and CPD impends cassava supply. It was also traced that there is a decrease of as much as 30\% export volume that affects the country's 1.5 billion dollar cassava industry [2].

Climate change and globalization may also affect cassava crops according to a report. It caused pests and diseases that threatened a multi-billion dollar industry and the primary food of millions of people in the world [4]. With the birth and continuous development of new technologies and ICT tools, there are research studies published and presented that provide effective solutions, timely strategies, and management to address problems and difficulties that can be adopted in monitoring the CPD that affect the production and crop yields of the plantation. This can be possibly solved with integrating the concept of drone-based image processing for detection and recognition of CPD that serves as the data entry, the used and adoption of GIS Technology for the representation of data through graphical mapping, and Web, Mobile and SMS Technology for the dissemination of information and provision of preventive measures.

The cassava farmers are not aware and not knowledgeable enough about the different diseases of cassava plants like CPD. They just basing the physical appearance of the cassava plant without knowing that the disease already infected the 
plant. And from that, they just accept the outcome of their production resulting low and some of the farmers switching other crops product having a high rate of production. And from that, the overall productions of cassava in the industry dropdown.

Monitoring systems are important for tracking current plantation status, changes, and predictions [5]. Monitoring systems as part of the control and management of CPD can be beneficial to farmers and the cassava industry since it can be used to monitor hectares of cassava plantation with the minimal number of laborers. Also, once suspected of CPD infections, they can plan for alternative crops and reduce their losses. Further, the system can serve as a tool to easily monitor cassava plantations and get notified in case an outbreak of the dreaded CPD occurs.

The Municipal Agriculture Office (MAO) of San Agustin, Isabela is the main user of the system. They manage all data and information in the system and have a privileged to provide access to system into the cooperative user (which is the EDCOR Development Cooperative), experts (researchers in cassava and pathologist), and registered farmers. EDCOR Development Cooperative is a group of a farmer in San Guillermo, Isabela. The cassava member farmers' of the cooperative are the ones who will feed data or information into the System. Applying the concept of Drone-based Image Processing for Recognition and Detection of CPD by scanning the cassava farmer farm areas. The Experts are the ones who send, upload, and disseminate preventive measures to the farmer's base from the data entry uploaded by the cooperative user. And the Cassava Farmers are the recipients of the System that receive and notified for preventive measures and request to scan the farm areas to the cooperative user.

The researchers aim to (1) develop the system interface of the Cassava Phytoplasma Disease monitoring and mapping system; (2) integration of technologies for; (2.1) graphical representation and mapping of GIS technology using Google Map API, and (2.2) SMS Technology for preventive measure notification using SMS gateway API; and (3) test the functionalities of the system for; (3.1) monitoring through mapping and SMS notification, (3.2) manage, send and receive preventive measure, and (3.3) generation of reports.

\section{RELATED LITERATURE}

\subsection{Geographic Information System (GIS)}

An information system called Geographical Information System (GIS) is used to manage information. It is a data system that deals particularly with geographic or spatial data needing voluminous information that can be accessed, manipulated, and used to provide timely output/results. The latitude and longitude coordinates are the basis in determining the geographic data by merely describing the location factors of an object or space [6].
With the use of GIS, the interpretation of spatial data become easy and simple to understand. Since GIS has enabled users to view spatial data in a readable format, ways of disseminating geospatial data and processing tools became cheap and easy. An organization like the DOST PAGASA Weather Forecast is distributing maps and processing tools [7].

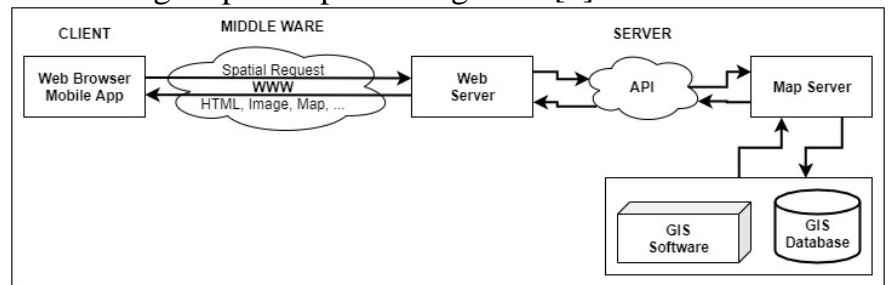

Figure 1: The GIS Architecture of the Study

As shown in Figure 1, performing the GIS analysis tasks is the same as the concept of the typical client-server three-tier architecture. The geo-processing is composed of the serverside and the client-side tasks. The server-side is consists of a web server, API as the mediator of GIS software, and the GIS database while the client-side is typically a web browser or Mobile App integrating GIS [7].

\subsection{Short Message Service (SMS)}

At present, the Short Message Service or the SMS is used to disseminate, send alert messages, and notifications. The SMS is an ICT-aided system providing users with reliable, cheaper, efficient, and effective means of communication that responds quickly [8]. It allows users to send and receive text messages via a mobile device [9]. Moreover, SMS technology is used in a wide perspective and now used in risk reduction and disaster warning purposes. On the other hand, mobile phones have more global usage than many other devices. SMS technology works depending on a service or network provider in order to connect to the network (as shown in figure 2) and the availability is wide open to many people having a mobile phone and it more generally used [10].

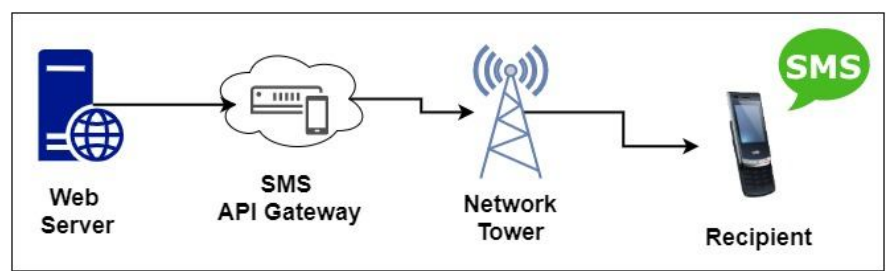

Figure 2: SMS Architecture

\subsection{Monitoring}

Traditionally, monitoring the cassava plants requires a lot of attention, inspection, and work to provide proper care and maintaining the healthiness of plants for better productivity. Monitoring the condition of the cassava areas in CPD infection for successful prevention and growth of production [11].

The concept of the monitoring system here served as a tool to access beneficial data and information such as report of percentage of infected cassava plantation; specific location of 
cassava plantation that is infected by CPD based from GPS coordinates; each location tag on the map consist of detailed information of the cassava farm such as land area, farmerowner, planted cassava variety, alternative plants planted on the infected disease infestation, estimated cassava production before and after; estimated possible loss of yields and production; possible income losses per cropping; and statistical summary report if there is an increase/decrease of infected areas. Moreover, a monitoring system should be installed, automated, and operated in a web interface for flexibility and accessibility in any device having a web browser [12] and having alert or notification of preventive measures through mobile phones to the cassava farmers.

\section{METHODOLOGY}

In the development of the system prototype, the Rapid Application Development (RAD) methodology [13] was employed. The diagram presented in Figure 3 is the conceptual framework of the system where it was categorized into three specific operational frameworks to answer the set objectives. The operational framework 1 is consists of the following: software methodology, software development tools, needed computer hardware, and peripherals, and the concept of the embedded system in image processing for detection and recognition of CPD. The operational framework 2 is the integration of GIS technology and the SMS technology using API. The operational framework 3 is the testing of the functionalities and features of the system using the image processing [14-15] input and API output, the data is used to simulate the monitoring/mapping of CPD infected, send SMS notification of the cassava farmer (beneficiaries) and generation of reports.

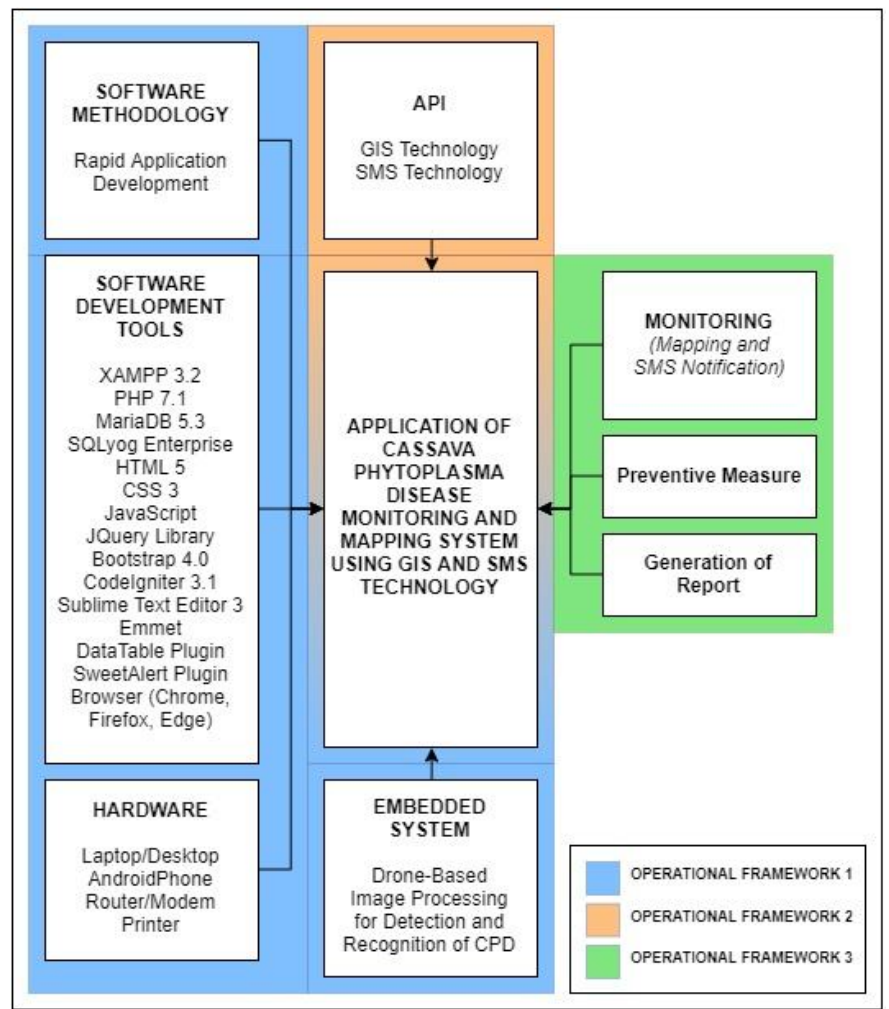

Figure 3: Conceptual framework of the system

\subsection{System development tools}

\subsubsection{Data Flow Diagram (DFD)}

The system process flow was conceptualized using the data flow diagram (DFD) as shown in Figure 4. The diagram explains the relationship between the different modules and tables of the database. The transaction details of the process flow presentation from the MAO acting as the system administrator, the cassava cooperative, involved experts, and the cassava farmers' roles and functions and vice versa were described.

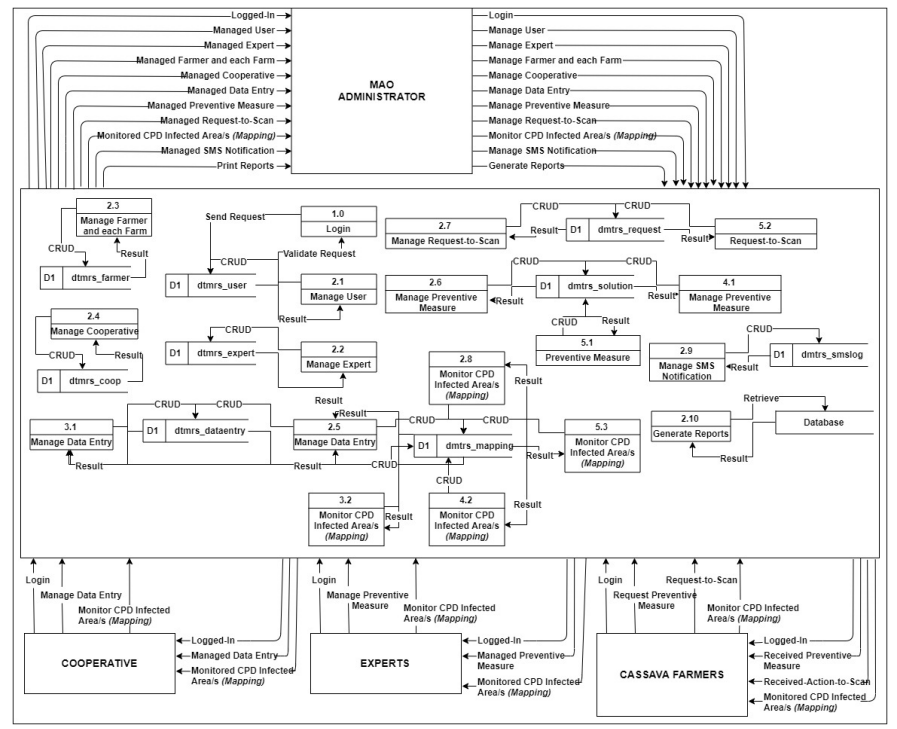

Figure 4: The Data flow diagram of the system

\subsubsection{Hardware specifications}

The hardware specifications and system requirements used in the development of the system both the minimum and the recommended specifications are shown in Table 1.

Table 1: Minimum and recommended hardware specifications

\begin{tabular}{|c|c|c|}
\hline & Minimum & Recommended \\
\hline \multicolumn{3}{|c|}{ Laptop / Desktop } \\
\hline Processor & $\begin{array}{c}\text { Intel Celeron N3050 @ } \\
\text { 1.6Ghz }\end{array}$ & $\begin{array}{c}\text { Intel Core i7-8550U } \\
@ 1.8 \mathrm{Ghz}\end{array}$ \\
\hline RAM & 2GB DDR3 & 4GB DDR4 \\
\hline GPU & Intel HD Graphics & $\begin{array}{c}\text { NVIDIA GeForce } \\
\text { MX150 }\end{array}$ \\
\hline Storage & 250GB & $500 \mathrm{~GB}$ \\
\hline Resolution & $1366 \times 768$ & $1920 \times 1080$ \\
\hline $\begin{array}{l}\text { Operating } \\
\text { System }\end{array}$ & Windows 7 Ultimate & Windows 10 Pro \\
\hline Browser & \multicolumn{2}{|c|}{ Any browser that supports JavaScript } \\
\hline \multicolumn{3}{|c|}{ Mobile Phone (Android) } \\
\hline Processor & Dual-Core & Quad-Core \\
\hline RAM & $512 \mathrm{MB}$ & $1.5 \mathrm{~GB}$ \\
\hline GPU & None & Mediatek \\
\hline Storage & 4GB & 8GB \\
\hline Resolution & $320 \times 480$ & $720 \times 1280$ \\
\hline $\begin{array}{l}\text { Operating } \\
\text { System }\end{array}$ & Android 5.1 Lollipop & $\begin{array}{c}\text { Android 6 } \\
\text { Marshmallow }\end{array}$ \\
\hline Browser & \multicolumn{2}{|c|}{ Any browser that supports JavaScript } \\
\hline
\end{tabular}




\subsubsection{Software used}

In the design and development of the system, front-end software, back-end software, and software development kit and tools were used.

For the front-end development, Hypertext Markup Language (HTML5) was used in creating the interface of the system. To add system design flexibility and interactivity, Cascading Style Sheets (CSS3) was used. While to make the system stable and will not crash easily, the Ajax (Asynchronous JavaScript and XML) was used. Lastly, Bootstrap 4, a CSS framework for the front-end design of the system and SweetAlert, a plugin in front-end design to customized, animate the popup alert box of the system was used.

For the back-end development, the SQLyog, a third-Party App for creating and managing the database in quick processing, proven reliability, ease and flexibility of use. The Hypertext Preprocessor (PHP 7.1), a programming language used to develop the system based on functionalities.

For additional software development kit and tools, Sublime Text 3 a text editor for creating the interface of the system and for creating a connection between the system and the server. The Android Studio 3, an IDE for android development, it is used for developing the mobile or android version of the system. Lastly, the Emmet, a plugin to code easily and accurately.

\subsection{The CPD Monitoring and Mapping System} architecture

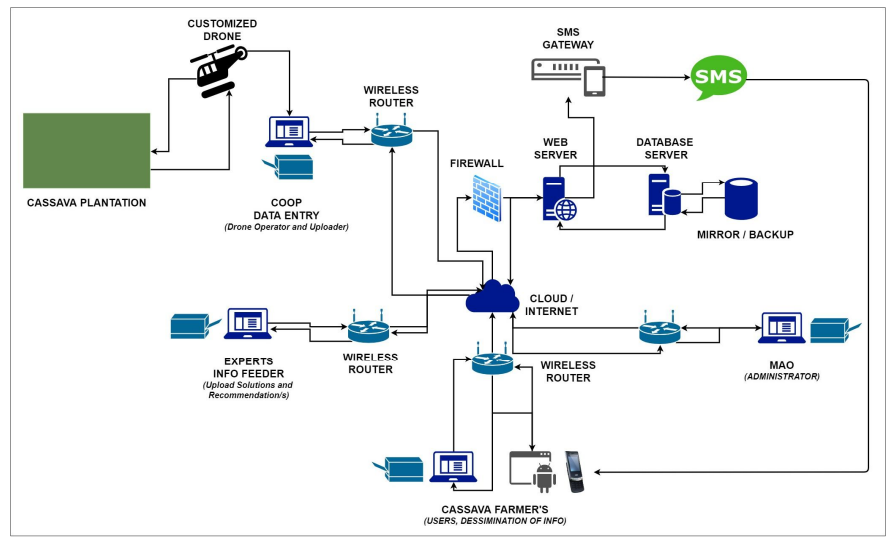

Figure 5: The CPD monitoring and mapping system architecture

Figure 5 shows the CPD monitoring and mapping system architecture where the process of the system shows how it works and flows in each corresponding user, transactions, modules, and network. The MAO is assigned as the administrator of the system, cooperative uploads data-entry to the system while experts as an information feeder, and the cassava farmers as recipient/beneficiaries.

\section{CONCLUSION AND FUTURE WORKS}

The conclusions were drawn based on the methodologies used and the results and discussion presented.

1. This paper presented the concept of the Cassava Phytoplasma Disease Monitoring and Mapping System using GIS and SMS Technology of the Municipal Agriculture Office of San Guillermo, Isabela, EDCOR Development Cooperative, Researchers and Pathologist, and Cassava Farmers. Using the GIS Technology provides the monitoring more interactive by its graphical-mapping representation and can be predictable, and through the SMS Technology is the dissemination of alerts and notifications of preventive measures. The monitoring and mapping of CPD can be easier. Therefore, the system may be a great help to the users stated especially the cassava farmers and the cassava industry.

2. The system integrates GIS Technology as shown in Figure 7 and SMS Technology as shown in Figure 8.

3. The system provides the functionalities in monitoring through mapping and SMS notification as shown in Figure 7 and Figure 8; manage, send and receive preventive measure as shown in Figure 9; and generation of reports as shown in Figure 10.

The conclusion further confirms that the objectives of the system were met.

\section{Acknowledgment}

Gratitude and acknowledgment go to the Department of Science and Technology, Philippine Council for Agriculture, Aquatic and Natural Resources Research and Development (DOST-PCAARRD) for approving the project and for providing funding support and assistance. To the Isabela State University for providing resources and technical assistance to the project team. To EDCOR Development Cooperative and the Local Government Unit of San Guillermo, Isabela particularly the Municipal Agriculture Office (MAO) for supporting the conduct of the project.

\section{REFERENCES}

M. A. El-Sharkawy, "Cassava biology and physiology," Plant Mol. Biol., vol. 56, no. 4, pp. 481501, 2004. https://doi.org/10.1007/s11103-005-2270-7

R. Argana, "Addressing the threats of Cassava phytoplasma disease," DOST-PCAARRD S T Media Serv., pp. 1-2, 2016. http://www.pcaarrd.dost.gov.ph/home/portal/index.ph p/quick-information-dispatch/2761-addressing-thethreats-of-cassava-phytoplasma-disease R. Dela Cruz, 'Fighting cassava witches' broom disease," Philipp. Star Glob., p. 1, 2016. T. X. Hoat, "New Agriculturist: Witches' broom - a curse on cassava," pp. 1-2, 2014. 
[5] P. Vijayakumar et al., "IoT based smart fuel monitoring system," Int. J. Recent Technol. Eng., vol. 8, no. 2, pp. 14-20, 2019. https://doi.org/10.35940/ijrte.A1146.078219

[6] S. S. Patil, D. R. Kulkarni, and P. D. Patil, "Watershed management for ingrul village in Sangli District, Maharashtra by using GIS," Int. J. Recent Technol. Eng., vol. 8, no. 2, pp. 1593-1599, 2019. https://doi.org/10.35940/ijrte.B2275.078219

[7] A.A. Alesheikh, H. Helali, H.A. Behroz, "Web GIS: Technologies and its application" https://www.isprs.org/proceedings/XXXIV/part4/pdfpa pers/422.pdf

[8] M.J.Z. Suaybaguio, "SMS technology as disaster warning and alert system as perceived by selected constituents of Davao Del Norte", International Refereed Research Journal, Vol.-VII, Issue - 1 (1), pp 38 - 50, 2016.

[9] Kable, "SMS (Short Message Service)," Retrieved March 17, 2014 from http://www.mobilecommstechnology.com/projects/sms/

[10] I. Yengin and A. Karahoca, "Educational potentials of SMS technology", Encyclopedia of Mobile Phone Behavior, pp. 11.

[11] K. Anitha, G. Keerthiga, and A. Hema Mailini, "Plant health monitoring system through image processing and defects overcoming through embedded system," Int. J. Recent Technol. Eng., vol. 8, no. 1, pp. 406-408, 2019.

[12] A. Gurdita, H. Vovko, and M. Ungrin, "A simple and low-cost monitoring system to investigate environmental conditions in a biological research laboratory",

https://doi.org/10.1371/journal.pone.0147140

[13] F. R. E. Labuanan, S.J. E. Tapaoan, and R. Q. Camungao, "Application of representation and fitness method of genetic algorithm for class scheduling system," Int. J. Recent Technol. Eng., vol. 8, no. 2, 2019.

[14] I. T. Plata, A. C. Taracatac, and E. B. Panganiban, "Development and testing of embedded system for smart detection and recognition of witches' broom disease on cassava plants using enhanced violajones and template matching algorithm," Int. J. Adv. Trends Comput. Sci. Eng., vol. 8, no. 5, pp. 2613-2621, 2019. https://doi.org/10.30534/ijatcse/2019/113852019

[15] E. B. Panganiban, A. C. Paglinawan, W. Y. Chung, and G. L. S. Paa, "A Novel Technique in Classifying Heart Diseases based on Electrocardiogram (ECG) Signals using Deep Learning and Spectrogram Image Analysis," Int. J. Adv. Trends Comput. Sci. Eng., vol. 8, no. 4, pp. 1734-1740, 2019. https://doi.org/10.30534/ijatcse/2019/102842019 